\title{
Predictors of Use of Contraception among Married Women of Reproductive Age in a Rural Area of Nepal
}

\author{
Tanuja Kumari Chaudhary, Birgunj Nursing Campus \\ Bhwan Kumari Dangol, Ph. D. Scholar, Mewar University \\ (bhuwankumaridangol@gmail.com) \\ Lalita Rai, Lecturer, Maharajgunj Nursing Campus \\ Mana Kumari Rai ${ }^{4}$, Professor, Maharajgunj Nursing campus
}

\begin{abstract}
Background: Universal access to family planning is a human right, central to gender equality and women's empowerment, and a key factor in reducing poverty. Use of contraception can prevent pregnancies related complication, helps in improving the health of mother and children and improve quality of life. Objective: to find out the predictors of use of contraception among married women of reproductive age (15-49 years). Methods: A descriptive cross-sectional study was adopted to find out the predictors of use of contraception among married women in Morang District. Cluster Random Sampling technique was used and sample size was 281. Data was collected by face to face interview technique by pretested questionnaire. Chisquare, bivariate, multivariable logistic regression model was used, and statistical significance was determined with a $95 \%$ confidence level. Results: Mean age of the respondents was $29.52 \pm 5.64$ years. Current contraceptive prevalence rate was $39.9 \%$. The significant predictors associated with use of contraception were education status of husband (Adjusted Odd Ratio $[A O R]=0.331,95 \% \quad C I=0.144-0.759)$, being desire of children $(A O R=2.564$, 95\%CI $1.060-6.198)$, spousal communication on contraception ( $A O R=5.120,95 \% C I=2.460-10.656)$, husband approval on contraception $(A O R=8.048,95 \% C I=4.047-16.006)$, and prior use of contraception $(A O R=0.122,95 \% \quad C I=0.055-0.272)$. The common barriers of utilization of contraception were husband disapproval (57.4\%) followed by fear of side effects (29.6\%). Conclusion: Contraceptive prevalence rates were low. So, continued joint efforts are required to increase use of contraception to improve maternal and child health. It is recommended to involve male in family planning.
\end{abstract}

Keywords:, Contraception, Married women, Predictors, Reproductive age, Rural area

\section{Introduction}

Birth control, also known as contraception and fertility control, is a method or device used to prevent pregnancy. Universal access to family planning (FP) is a human right, central to gender equality and women's empowerment, and a key factor in reducing poverty and achieving the Millennium Development Goals. Gender equality, women's health, child survival and HIV prevention are benefit of FP. For adolescents, improved access to comprehensive sexuality education and modern contraception increases opportunities throughout their lives, including for higher levels of education, fewer pregnancies, a later and healthier start to childbearing, and greater ability to engage in income-producing activity (United Nation Population Fund, 2012). Despite the enormous benefits of family planning services, the uptake of the service still remains low in developing countries. This has resulted into high rates of unwanted pregnancies, unplanned deliveries, unsafe abortions and maternal mortalities (Eliason et al., 2013). 
An analysis of 172 developing countries reveals that contraceptive could reduce maternal death by $44 \%$. Satisfying unmet need for contraception could prevent another maternal death by $29 \%$ (Ahmed, Quingfeng, Lie, \& Tsui, 2012).Globally; among 55 million pregnancies 40\% were unplanned in 2012. Of these, abortion (50\%), unplanned birth (38\%) and maternal death (13\%) related to complication of abortion (Sedgh, Singh, \& Hussain, 2014).

Only $43 \%$ of married women use modern contraception (Ministry of Health Population, New ERA \& ICF International, 2012). In Nepal, the Contraceptive Prevalence Rate (CPR) has increased by $2 \%$ per year between the 1996 and 2006. CPR low coverage and unmet needs remain a challenge to meet the planned CPR level of 52 by 2021 (Ministry of Health and Population, Government of Nepal, 2015).

More than two-fifth of the currently pregnant women reported that their current pregnancy was unintended and negative association with the social and health outcomes for both mothers and children (Adhikari, Soonthorndhada \& Prasartkul, 2009). Neonatal mortality rate was 54/1,000 live births among less than two years of birth spacing but 23/1,000 live births among more than two years of spacing (Paudel, Thapa, Shedain \& Paudel, 2013).

Education status of their husbands, women have no desire of children, spousal communication on contraception, husband's support, prior use of contraception were significantly associated with use of contraception. Predictors of use of contraception can help in making recommendation regarding the appropriate development policies and strategies to reorient and encourage the adaptation of family planning services to reduce maternal and child's mortality.

\section{Methods}

Descriptive Cross-sectional research design was adopted for the study to find out predictors of use of contraception among married women of reproductive age (15-49 yrs) in ShishbaniBadahara Village Development Committee (VDC) of Morang district. VDC was selected purposively and Cluster Random Sampling was adopted for selecting the respondents. The sample size was 281. Data was collected by interview method from 28 February to 27 March, 2016. Ethical approval was obtained from concerned authority. Verbal consent was obtained from each respondent. Confidentiality was maintained by giving code number. After finishing the interview, information was provided to make aware about contraception. Chi-square, bivariate, and multivariate (binary logistic regression) analysis is used with statistical standard 95\% confidence interval (CI). Unadjusted and adjusted odds ratio were calculated to measure the net effect of variables on use of contraception.

\section{Result}

TABLE 1

Socio-demographic Characteristics of respondents

\begin{tabular}{lrr}
\hline Socio-demographic Characteristics & \multicolumn{1}{c}{ Women's } & Women Husbands' \\
\cline { 2 - 3 } & \multicolumn{1}{c}{ Number (\%) } & \multicolumn{1}{c}{ Number (\%) } \\
\hline Age in Years(n=281) & $64(22.8)$ & $25(8.9)$ \\
$15-24$ & $135(48.0)$ & $100(35.6)$ \\
$25-34$ &
\end{tabular}


$35-44$

44 and above

Mean

Range

Education Status $(n=281)$

Illiterate

Literate

If literate,

\section{Level of Education}

Read and write only

Primary level

Secondary level

Higher secondary level

Bachelor level and above

Occupation Status ( $\mathbf{n = 2 8 1 )}$

Home maker

Daily wages worker

Business

Services

Agriculture

Migrant worker
$82(29.2)$

$124(44.1)$

32 (11.4)

$29.52 \pm 5.649$ Years

$19-40$

$34.63 \pm 7.479$ Years

$120(42.7)$

85 (30.2)

161 (57.3)

$196(69.8)$

$\mathrm{n}=161$

$\mathbf{n}=196$

22(13.7)

15 (7.7)

$42(26.1)$

$78(39.8)$

67 (41.6)

65 (33.2)

25 (15.5)

$32(16.3)$

$5(3.1)$

$6(2.1)$

199 (70.8)

37 (13.2)

$151(53.7)$

31 (11.0)

32 (11.4)

$8(2.8)$

27 (9.6)

$6(2.1)$

23 (8.2)

$48(17.1)$

Nearly half (48\%) of the women were age group 25-34 years with the mean age of 29.52 \pm 5.649 years and range from 19-40 years. Similarly among husband, $44.1 \%$ were age group of 35-44 years with mean age mean \pm SD: $34.63 \pm 7.479$ and range from $20-50.57 .3 \%$ respondents and $69.8 \%$ of respondent's husbands were literate. Majority of the respondents occupation were home maker $(70.8 \%)$ and husband's occupation were daily wages $(53.7 \%) .55 .6 \%$ of women's ages at first marriage were less or equal to 18 years with the mean age at time of marriage was $19.10 \pm 2.79$ years. The mean marital duration was $10.42 \pm 6.235$ and $47.7 \%$ women were marital duration of $>10$ years. Majority $(82.9 \%)$ of the respondents were Aadibasi Janjati, $49.5 \%$ income was not sufficient for 1 year, and $68 \%$ were stay in nuclear family. All women $(100 \%)$ were heard about family planning, $61.2 \%$ received information from health professionals.

TABLE 2

Reproductive Characteristics and Use of Contraception

\begin{tabular}{lrr}
\hline Variables & Number & Percentage \\
\hline Ever Pregnant $(\mathbf{n = 2 8 1})$ & & \\
$\quad$ Yes & 269 & 95.7 \\
$\quad$ No & 12 & 4.3 \\
Pregnancy Status (n=269) & 213 & 79.2 \\
$\quad$ Wanted & 56 & 20.8 \\
$\quad$ Unwanted & & \\
Seeking for Abortion (n=56) & 6 & 10.7 \\
$\quad$ Yes & 50 & 89.3 \\
$\quad$ No & & \\
\hline
\end{tabular}




\begin{tabular}{lrr}
\hline Number of Living Children (n=269) & & \\
No child & 3 & 1.1 \\
One & 109 & 40.5 \\
Two & 108 & 40.1 \\
Three & 30 & 11.2 \\
$\quad$ Four & 16 & 5.9 \\
$\quad$ Five & 3 & 1.1 \\
Sex of Children (n=266) & 187 & 70.3 \\
$\quad$ Son or both (son and daughter) & 79 & 29.7 \\
$\quad$ Only Daughter & & \\
Desire of Children (n=281) & 131 & 49.9 \\
$\quad$ Yes & 150 & 54.1 \\
$\quad$ No & 113 & 86.3 \\
Number of Desire Children (n=131) & 18 & 13.7 \\
$\quad$ One & & \\
$\quad$ Two & 90 & 68.7 \\
Intension to Children (n=131) & 23 & 17.6 \\
$\quad$ Have few children & 18 & 13.7 \\
$\quad$ Need for son & & \\
$\quad$ Others & 141 & 52.4 \\
Place of Last Child Deliver (n=269) & 128 & 47.6 \\
$\quad$ Non Institutional &
\end{tabular}

Others: Death of child, husband desire of daughter, parental influence, no children

Table 2 reveals that majority $(95.7 \%)$ of women had pregnant once during their lives time, $79.2 \%$ were wanted pregnancy, $89.3 \%$ were not experience of abortion, $40.5 \%$ of the women had one children. Regarding to sex of children, $70.3 \%$ of women had son and daughter. Likewise, $49.9 \%$ of women were expressed desire for children, and $86.3 \%$ desired to have one more children. Among desired to have children in the future, $68.7 \%$ respondents expressed a desire to bear more children. $52.4 \%$ women were delivered her last child at non institution.

TABLE 3

\section{Knowledge of Respondents about Contraception}

\begin{tabular}{lrr}
\hline Knowledge on Contraception & Number & Percentage \\
\hline Benefits of Contraception * & & \\
Prevention of unwanted pregnancies & 119 & 42.3 \\
Happy family & 101 & 35.9 \\
Birth spacing & 79 & 28.1 \\
No need for another child & 45 & 16.0 \\
Delay in first child & 37 & 13.2 \\
Improve health of mother and child & 46 & 16.4 \\
Don't know & 74 & 26.3 \\
Contraceptive Methods * & & \\
Injectables (Depo provera) & 252 & 89.7 \\
Oral contraceptive pills & 168 & 59.8 \\
Norplant/ implant & 56 & 19.9 \\
Intrauterine contraceptive device (IUCD) & 55 & 19.6 \\
Male condom & 52 & 18.5 \\
Female sterilization & 53 & 18.9
\end{tabular}


Vasectomy

Place of Available of Contraceptive Methods*

Public health institutions/ health post

Medical shop

Private clinic

Hospital

FCHV

Don't know

*: Multiple responses

Table 3 shows that, majority (42.3\%) or the respondents answered benefits of contraception was prevention of unwanted pregnancies. Majority (89.7\%) respondents answered that depoprovera is a method of contraception. Concerning the place of available of contraceptives, $79.7 \%$ responded mentioned on public health institutions.

TABLE 4

\section{Sociocultural Factors Associated with Use of Contraception}

$\mathbf{n}=\mathbf{2 8 1}$

\begin{tabular}{lrr}
\hline Sociocultural Factors & Number & Percentage \\
\hline Spousal Communication on Contraception & & \\
$\quad$ Discussed & 94 & 33.5 \\
$\quad$ Not discussed & 187 & 66.5 \\
Husband Approval on Contraception & & \\
$\quad$ Approved & 137 & 48.8 \\
$\quad$ Not Approved & 144 & 51.2 \\
Decision on Contraception & & \\
$\quad$ Husband (independently) & 222 & 79.0 \\
Wife (independently) & 52 & 18.5 \\
Mutual (husband and wife) & 7 & 2.5 \\
\hline
\end{tabular}

Table 4 shows the socio-cultural factors of women of reproductive age with use of contraception. Majority $(66.5 \%)$ of them did not discussed about contraception with husband and $51.2 \%$ perceived that husband do not approve to use of contraception. Majority (79\%) of respondents answered that husband independently take decision on contraception.

Table 5

Contraceptive Usages among Respondents

\begin{tabular}{lcr}
\hline Contraceptive Usages & Number & Percentage \\
\hline Prior Use of Contraception $(\mathbf{n = 2 8 1})$ & 120 & 42.7 \\
$\quad$ Yes & 161 & 57.3 \\
$\quad$ No & & \\
Current Contraceptive Use (n=281) & 112 & 39.9 \\
$\quad$ Yes & 169 & 60.1 \\
$\quad$ No & & \\
Use of Different Contraceptive Methods (n=112) & 50 & 44.6 \\
$\quad$ Depot Provera (Sangini) & 16 & 14.3
\end{tabular}




\begin{tabular}{lrr}
\hline IUCD & 4 & 3.6 \\
Implant & 1 & 0.9 \\
Condom & 1 & 0.9 \\
Female sterilization & 40 & 35.7 \\
\hline
\end{tabular}

Table 5 more than half $(57.3 \%)$ of respondents never use contraception. The most common reason for discontinuation of contraception were developing side effects (51.1\%), and husband disapproval (21.8\%). Majority (60.1\%) respondents answered, they do not use contraception. Among user, injectable (44.6\%), IUCD (0.9\%) and male condom $(0.9 \%)$ were used.

TABLE 6

\section{Reason for Use and not use of Contraceptive}

\begin{tabular}{lrr}
\hline Contraceptive Usages & Number & Percentage \\
\hline Reasons for Use $(\mathbf{n = 1 1 2})$ & & \\
Birth limiting & 30 & 71.4 \\
Birth spacing & & 28.6 \\
Reasons for not Use * (n=169) & 97 & 57.4 \\
$\quad$ Husband disapproval & 50 & 29.6 \\
Fear of side effects & 41 & 24.3 \\
Not available of suitable method & 33 & 19.5 \\
Need of another child & 32 & 18.9 \\
Husband is not here & 21 & 12.4 \\
Breast feeding & 20 & 11.8 \\
Unknown about method & & \\
Future Intension to Use $(\mathbf{n}=\mathbf{1 6 9})$ & 103 & 60.9 \\
$\quad$ Not intend to use & 66 & 39.1 \\
$\quad$ Intend to use & &
\end{tabular}

Table 6 reveals, the most common reason for use of contraception was birth limiting (71.4\%). The respondent answered reason of not use contraception was husband's disapproval $(57.4 \%)$, unknown aout methods (11.8\%). Majority (60.9\%) of respondents were not intend to use contraception in future.

TABLE 7

Health Service Factors Associated with Use of Contraception

\begin{tabular}{lrr}
\hline Health Service Factors & Number & Percentage \\
\hline Preferred Place to Get Contraception & & \\
Health post & 158 & 56.2 \\
Medical shop & 105 & 37.4 \\
Hospital & 18 & 6.4 \\
Perception on Cost & 271 & \\
$\quad$ Affordable & 10 & 36.4 \\
$\quad$ Not Affordable & & 3.6 \\
Convenience to Service & 249 & 88.6 \\
$\quad$ Yes & 32 & 11.4 \\
No &
\end{tabular}


ISSN: 2362-1303 (Paper) | elSSN: 2362-1311(Online)

JOURNAL OF ADVANCED ACADEMIC RESEARCH (JAAR)

October 2016

\begin{tabular}{lrr} 
Easily Available Method & & \\
Yes & 228 & 81.1 \\
No & 53 & 18.9 \\
Satisfaction towards Services $(\mathbf{n = 1 1 2}) * *$ & & \\
Yes & 95 & 84.8 \\
No & 17 & 15.2 \\
\hline
\end{tabular}

**those respondents were current user

Table 7 shows that more than half $(56.2 \%)$ respondents replied that health post was preferred place to usually get contraceptives. Majority (96.4\%) of them perceived that contraception were affordable, $88.6 \%$ of women said that it was convenient and $81.1 \%$ of the women were replied it is easily available. Among the current user, $84.4 \%$ of the respondents were satisfied towards service.

\section{TABLE 8}

Predictors of Use of Contraception among Married Women of Reproductive Age

\begin{tabular}{|c|c|c|c|c|}
\hline $\begin{array}{l}\text { Predictors of use of } \\
\text { contraception }\end{array}$ & $\begin{array}{r}\text { Unadjusted OR } \\
(95 \% \text { CI })\end{array}$ & $\begin{array}{c}p- \\
\text { value }\end{array}$ & $\begin{array}{r}\text { Adjusted OR } \\
(95 \% \text { CI })\end{array}$ & $\frac{\mathrm{n}=281}{p \text {-value }}$ \\
\hline \multicolumn{5}{|l|}{ Age of Women } \\
\hline$\leq 30$ & Reference & & Reference & \\
\hline$>30$ & $1.864(1.146-3.034)$ & $0.012 *$ & $1.295(0.584-2.872)$ & 0.525 \\
\hline \multicolumn{5}{|l|}{ Marital Duration } \\
\hline$\leq 5$ & Reference & & Reference & \\
\hline$>5$ & $2.179(1.259-3.772)$ & $0.005^{*}$ & $1.926(0.666-5.573)$ & 0.205 \\
\hline \multicolumn{5}{|c|}{ Education Status of Women } \\
\hline Illiterate & Reference & & Reference & \\
\hline Literate & $0.573(0.353-0.931)$ & $0.024 *$ & $1.421(0.648-3.116)$ & 0.380 \\
\hline \multicolumn{5}{|c|}{ Education Status of Husband } \\
\hline Illiterate & Reference & & Reference & \\
\hline Literate & $0.462(0.275-0.775)$ & $0.003 *$ & $0.331(0.144-0.759)$ & $0.009 *$ \\
\hline \multicolumn{5}{|c|}{ Occupation status of Women } \\
\hline Home maker & Reference & & Reference & \\
\hline Working & $1.803(1.071-3.036)$ & $0.026^{*}$ & $1.605(0.770-3.346)$ & 0.206 \\
\hline \multicolumn{5}{|c|}{ Number of Children $(n=266)$} \\
\hline$\leq 2$ & Reference & & Reference & \\
\hline$>2$ & $2.719(1.442-5.126)$ & $0.002 *$ & $1.308(0.532-3.214)$ & 0.535 \\
\hline \multicolumn{5}{|l|}{ Desire of Children } \\
\hline Yes & Reference & & Reference & \\
\hline No & $3.368(2.021-5.614)$ & $0.000 *$ & $2.564(1.060-6.198)$ & $0.037 *$ \\
\hline \multicolumn{5}{|c|}{ Place of Last Child Delivery } \\
\hline Non Institutional & Reference & & Reference & \\
\hline Institutional & $0.599(0.367-0.978)$ & $0.040 *$ & $0.700(0.330-1.484)$ & 0.353 \\
\hline \multicolumn{5}{|c|}{ Spousal Communication on Contraception } \\
\hline Not discuss & Reference & & Reference & \\
\hline Discuss & $3.447(2.055-5.783)$ & $0.000 *$ & $5.120(2.460-10.656)$ & $0.000 *$ \\
\hline \multicolumn{5}{|c|}{ Husband Approval on Contraception } \\
\hline Not approval & Reference & & Reference & \\
\hline Approval & $7.653(4.424-13.238)$ & $0.000 *$ & $8.048(4.047-16.006)$ & $0.000 *$ \\
\hline \multicolumn{5}{|c|}{ Prior Use of Contraception } \\
\hline No & Reference & & Reference & \\
\hline
\end{tabular}




\begin{tabular}{lllll} 
Yes & $0.545(0.332-0.893)$ & $0.015^{*}$ & $0.122(0.055-0.272)$ & $0.000^{*}$ \\
\hline
\end{tabular}

The model was fit as shown by Hosmer and Lemeshow test of significance $(p=0.677)$

*: Significant $\mathrm{p}$-value at $<0.05,95 \% \mathrm{CI}=95 \%$ Confidence Interval

Table 8 depicts that all significant variables in bivariate analysis were put into binary regression model. Education status of their husbands' (AOR=0.331; 95\% CI=0.144-0.759, $p=0.009$ ), Women have no desire of children $(\mathrm{AOR}=2.564 ; 95 \% \mathrm{CI}=1.060-6.198, p=0.037)$, spousal communication on contraception ( $\mathrm{AOR}=5.120 ; 95 \% \mathrm{CI}=2.460-10.656, p=0.000$ ), women perception towards husband support $(\mathrm{AOR}=8.1048,95 \% \mathrm{CI}=4.047-16.006, p=0.000)$, prior use of contraception (AOR $=0.122 ; 95 \% \mathrm{CI}=0.055-0.272, p=0.000)$ were significantly associated with use of contraception.

Age of women, marital duration, women education and occupational status, number of living children, place of last child delivery were not significantly associated with use of contraception. Therefore these variables are not considered as the predictors of use of contraception.

\section{Discussion}

The present study showed that $39.9 \%$ of married women of reproductive age group were use modern contraception. This finding is consistent with MOHP, New ERA, \& ICF International, (2012) and Keyal and Moore (2014) that was 43\% and 39\% of married women were used modern contraception. Depoprovera was the most (44.6\%) commonly used contraceptive methods. This finding is similar to the study of Rayamajhi et al.(2013), and Bhandari et al., (2013).

Majority (57.4\%) reasons for not using family planning among women were husband opposition. But the findings of Gizaw \& Regassa, (2011); showed that most important reason for not utilizing family planning service were fertility reason.

Education status of women's were significantly association with contraception $(\mathrm{OR}=0.573$, $95 \% \mathrm{CI}=0.353-0.931, p=0.024)$. This finding is supported by findings of Keyal and Moore (2014); and Debebe et al., (2014); the findings showed that level of education of the women has a significant association with modern contraception utilization.

Literate husband were less likely to use of contraception as compared to illiterate husband $(\mathrm{AOR}=0.331 ; 95 \% \mathrm{CI}=0.144-0.759, \mathrm{p}=0.009)$. This is inconsistent with Shrivastava, (2012) and Khan et al., (2012); the literacy status can definitely have an impact on motivating a couple to adopt any contraceptives method for spacing.

Occupation of women was significant association with use of contraception; working women were more likely to use contraception than house maker $(\mathrm{OR}=1.803,95 \% \mathrm{CI}=1.071-3.036)$. This finding was consistent with Igbodekwe et al., (2014); the findings showed that working women were $43 \%$ more likely to use of contraception $(\mathrm{AOR}=1.432,95 \% \mathrm{CI}=1.299-1.580)$ in Nigeria.

Family income sufficient for 1 year were more likely to currently use contraception compared to income is not sufficient for one year but statistically insignificant with contraception. similar findings of Igbodekwe et al., (2014); Lakshmi \& Neetha (2013); Tekelab et al., (2015); Debede et al., (2014); contraceptive usages were significantly associated with wealth index. 
Significant association was found between marital duration and contraception in $(\mathrm{OR}=2.179$, 95\% CI=1.259-3.772). The finding is inconsistent with study Soe et al.,(2012); longer duration of marriage were significantly less likely to practice contraception $(\mathrm{AOR}=0.03 ; 95 \% \mathrm{CI}=0.002$ $0.59)$.

Numbers of living children were associated with use of contraception $(\mathrm{OR}=2.719,95 \% \mathrm{CI}=$ 1.442-5.126, $p=0.002$ ). It implies that married women who have $>2$ children were 2.7 times more likely to use of contraception. The finding is consistent with Telelab et al., (2015); that those women were not desire of more children in the future were 2.6 times more likely to use of contraception $(\mathrm{AOR}=2.60,95 \% \mathrm{CI}=1.48-4.56)$.

Prior use of contraception were the strong predictors of contraception (AOR $=0.122 ; 95 \%$ $\mathrm{CI}=0.055-0.272, p=0.000$ ). This finding was supported by Eliosan et al. (2013); women who had history of contraceptive use were strong determinants of use of contraception.

Sex of living children was not significant predictors of contraception and married women who have son or both were more likely to use of contraception than those married women have daughter only $(\mathrm{OR}=1.605,95 \% \mathrm{CI}=0.929-2.773)$. This might be due to cultural reason. This reason was supported by Dahal et al., (2008), Kamal (2009), women who had only daughter $(43 \%)$, and both (61.2\%) more likely to use any contraceptive method.

Place of last child delivery was significantly association with contraception (UOR $=0.599,95 \%$ $\mathrm{CI}=0.367-0.978, p=0.040$ ). In contrast, the study done by Lauria et al., (2014) showed that women who received counseling on prenatal to postnatal period were more likely to use effective contraceptives.

Spousal communication about contraception is a strong predictors of use of contraception. Women who were discussed with their husband about contraception were 5.1 times more likely to use of contraception. This finding is consistent with the study by Link (2011); that showed spousal communication on contraceptives was strong positive impact. Women perception of husband approval on use of contraception were statistically significant (AOR=8.048, $95 \% \mathrm{CI}=4.047-16.006, p=0000)$. The finding is consistent with the study of Mohammed et al. (2014); married women who perceive that their husband approve the use of contraception were 2.8 times more likely to use modern contraception.

Knowledge on contraception were not statistically significant with contraception (OR=2.000. 95\% CI=0.922-4.340, $\mathrm{p}=0.075$ ). This finding was supported by Soe et al., (2012); and contrast, with the findings of Raymajhi et al., Debede et al., (2014) and Robert et al., (2015); knowledge was associated with use of contraception

Decision on contraception was not significantly associated with the use of contraception. In contrast Tekelab et al., (2015) showed that women who had made joint decision about fertility issue with their husband were more likely to use of contraception. Perception of cost is significantly associated with use of contraception $(\mathrm{p}=0.007)$. The finding is supported by Soe et al. (2012); perception of affordability with regards to cost is one factor which encourages the women to continue use contraception. Convenience to services was not statistically significant association with contraception $(\mathrm{OR}=1.527,95 \% \mathrm{CI}=0.693-3.369, p=0.291)$. Those women have convenience to service were more likely to use contraception than those were not convenience to service. This might be due to small study area and small sample size. 


\section{Conclusion}

Contraceptive prevalence rates were low. Educational status of husband, desire of children, prior use of contraception, spousal communication on contraception, and husband approval on use of contraception are strong predictors that contribute to the use of contraception. Role of men in promoting family planning utilization is generally low. Predictors of use of contraception can help in making recommendation regarding the appropriate development policies and strategies to reorient and encourage the adaptation of family planning services. So, continued joint efforts are required to increasing use of contraception.

\section{References}

Adhirkari, R., Soonthorndhaada, K. \& Prasartkul, P. (2009).Correlates of unintended pregnancies among currently pregnant married women in Nepal.BioMed Central, International Health Human Right, 9(17), 1-10. doi:10.1186/1472-698x

Ahmed, S., Quingfeng., L.I., Lie, LI., \& Tsui, A.O. (2012). Maternal death averted bycontraceptive use:an analysis of 172 countries. The Lancet, 380 (9837), 111125.http://dx.doi.org/10.1016/S0140-6736(12)60478-4

Bhandari, N., Shrestha, G. K. \& Thakuri, P. C. (2013). Factor affecting contraceptive useamong married women of reproductive age. Journals of College of Medical Sciences, Nepal, 9(4), 24-29. doi: http://dx.doi.org/10.3126/jcmsn.v9i4.10233

Dahal, G. P., Padmadas, S. S., \& Andrew Hinde, P. R. (2008).Fertility limiting behaviorand contraceptive choice among men in Nepal. International Family Planning Perspectives, 34(1), 6-14. doi: 10.1363/ifpp.34.006.08

Debede, Z., Tachbele, E., \& Dereje, N. (2014). Predictors of modern contraceptive utilization among married reproductive age in Maha District, Southern Ethiopia. International Journal of Research, 1(11), 322-336. Retrieved from https://internationaljournalofresearch

Eliason, S., Baiden, F., Asare, G.Q., Hayfron, Y.G., Bonsu, D., Philips, J., \& Asare, K. A. (2013). Factors influencing the intention of women in rural Ghana to adopt postpartum family planning. Reproductive Health, 10, (34). doi: 10.1186/1742-4755-10-34

Gizaw, A., \& Regassa, N. (2011). Family planning service utilization in Mojo town, Ethiopia: A population based study. Journals of Geography and Regional Planning, 4(6), 355-63. Retrieved from http://www.academicjournals.org/article/article1381842432 Geda\%20and\%20Regassa.pdf

Igbodekwe, F. C., Olandinmeji, O., Olandimeji, K. E., Adeoje, I. A., Akpa, O.M., \& Lawson, L. (2014). Utilization of modern contraceptive among women of childbearingage in resource constraint setting: Evidence from 2008 National Demographic and Health Survey in Nigeria. Journal of Health Science, 4(3),72-78. doi:10.5923/j.health.20140403.04

Keyal, N. K., \& Moore, M. (2014). Contraception in eastern Nepal:a study of knowledge and use. Journal of Universal College of Medical Sciences, 2(6), 15-20. Retrieved from www.nepjol.info/index.php/JUCMS/article

Kamal, S. M. (2009). Contraceptive use and method choice in urban slum of Bangladesh. International conferences on family planning. Retrieved from http://fpconference.org/2009/media/DIR_169701/15f1ae857ca97193ffff83a4ffffd524.pdf

Lauria, L., Donati ,S., Spinelli , A., Bonciani , M., \&Grandolfo, M. E.(2014). The effectof contraceptive counselling in the pre and post-natal period on contraceptive use at three months after delivery among italian and immigrant women. Ann Ist Super Sanita, 50 (1), 5461. doi: 10.4415/ANN_14_01_09

Lakshmi, M. M.,\& Neetha, S. R., (2013). Contraceptive practices among reproductiveage group of women in Justice KS Hegde Medical College Hospital, Mangalore. International Journal of 
Reproduction, Contraception, Obstetrics and Gynecology, 2(1), 39-46. doi: 10,5455/23201770.ijrcog20130207

Link, C. F. (2011). Spousal Communication and Contraceptive Use in Rural Nepal: An Event History Analysis. Studies in Family Planning, 42(2), 83-92. http://dx.doi.org/10.1111/j.17284465.2011.00268.x

Ministry of Health and Population (MOHP) [Nepal], New ERA. \& ICF International Inc. (2012).Nepal Demographic and Health Survey 2011. Kathmandu, Nepal: Ministry of Health and Population, New ERA, and ICF International, Calverton, Maryland.

Ministry of Health and Population (MOHP), Government of Nepal. (2015). Nepal Health Sector Strategy Plan 2015-2020. Government of Nepal, Ministry of health and population, Kathmandu, Nepal.

Mohammed, A., Woldeyohannes, D., Feleke, A., \& Megabiaw, B. (2014).Determinantsof modern contraceptive utilization among married women of reproductive age group in North Shoa Zone, Amhara Region, Ethiopia.Reproductive Health, 11(13),1-7.doi: 10.1186/1742-4755-1113

Paudel, D., Thapa, A., Shedain, P. R., \&Paudel, B. (2013).Trends and determinants of neonatal mortality in Nepal: Further analysis of the nepal demographic and health surveys, 2001-2011. Calverton, Maryland, USA: Nepal Ministry of Health and Population, New ERA, and ICF International.

Rayamajhi, R. B., Ghimire, A., Niraula, S.R., Budhathoki, S.S., Khanal, V. K., \& Pokharel, P.K. (2013). A descriptive study on contraceptive practices among mothers in belhara VDC of Dhankuta District, Nepal. Journal of Chitwan Medical College, 3(6), 34-37. Retrieved from http://www.nepjol.info/index.php/JCMC/article/viewFile/9552/7851

Robert, M. K., Ndwiga, T., \&Okong'o , S. (2015). The use of modern contraceptive among womenof child bearing age attending MCH/FP clinic att Uasin Gishu sub country hospital, Kenya. Science Journal of Public Health, 3 (4), 500-507.doi: 10.11648/j.sjph.20150304.17

Sedgh, G., Singh, S., \& Hussain, R. (2014). Intended and unintended pregnancies worldwide in 2012 and recent trends. Studies Family Planning, 45 (3), 301-314. Retrieved from https://www.guttmacher.org/pubs/journals/j.1728-4465.2014.00393.x.pdf

Shrivastava, P.S. (2012). Contraceptive practices adopted by women attending in urban health center. African Health Sciences, 12 (4), 416-421. Retrieved from http://www.ajol.info/index.php/ahs/article/view/85070

Soe, H. H. K., Than, N. N., Kaul, A., Kumar, S., \&Somrongthong, R. (2012). Determinants of contraceptive usage among Myanmar migrant women in Phang-Nga Province Thailand. Journal of Medicine and Medical Sciences,3(11), 721-728. Retrieved fromhttp://www.interesjournals.org/JMMS.

United Nation Population Fund.(2012). Choice not chance: family planning strategy 2012-2020. Retrieved from http://www.unfpa.org/sites/default/files/pub-

pdf/UNFPA\%20CHOICES\%20NOT\%20CHANCE_final.pdf 